\title{
Synthetic biology: ethical ramifications 2009
}

\author{
Paul Rabinow · Gaymon Bennett
}

Received: 26 May 2009/Revised: 3 August 2009/Accepted: 14 August 2009

(C) The Author(s) 2009. This article is published with open access at Springerlink.com

\begin{abstract}
During 2007 and 2008 synthetic biology moved from the manifesto stage to research programs. As of 2009, synthetic biology is ramifying; to ramify means to produce differentiated trajectories from previous determinations. From its inception, most of the players in synthetic biology agreed on the need for (a) rationalized design and construction of new biological parts, devices, and systems as well as (b) the re-design of natural biological systems for specified purposes, and that (c) the versatility of designed biological systems makes them suitable to address such challenges as renewable energy, the production of inexpensive drugs, and environmental remediation, as well as providing a catalyst for further growth of biotechnology. What is understood by these goals, however, is diverse. Those assorted understandings are currently contributing to different ramifications of synthetic biology. The Berkeley Human Practices Lab, led by Paul Rabinow, is currently devoting its efforts to documenting and analyzing these ramifications as they emerge.
\end{abstract}

Keywords Synthetic biology - Human practices . Social consequences $\cdot$ ELSI $\cdot$ SynBERC

P. Rabinow · G. Bennett $(\square)$

Department of Anthropology and the Synthetic Biology

Engineering Research Center, University of California,

Berkeley, CA, USA

e-mail: gaymon.bennett@berkeley.edu

URL: www.ars-synthetica.net; www.anthropos-lab.net;

www.synberc.org

P. Rabinow

e-mail: rabinow@berkeley.edu
What is synthetic biology? Just a few years ago this question could not have been answered with any degree of specificity. Rather, for a small group of researchers the question was: What do we want synthetic biology to be? At that point, synthetic biology existed as informally connected visions of how one might make biological engineering robust and standardized. During 2006 and 2007 two major obstacles were cleared for testing whether, and if so, how that imagined discipline could be made operational. First, the stirring, if inchoate, visions for synthetic biology were turned into crisp manifestos: discursively coherent, power-point friendly, declamations of broad programmatic objectives. The manifestos included a sketch of preliminary design principles conceived to realize the initial steps. Second, the manifestos, in turn, were crafted into proposals for new research venues and infrastructures capable of new modes of collaboration and production.

In 2006 Jay Keasling, a professor of chemistry at UC Berkeley, with colleagues at MIT, Harvard, UCSF, and Prairie View A\&M, submitted a proposal to the National Science Foundation for an Engineering Research Center in synthetic biology—SynBERC (http://www.synberc.org). SynBERC's stated goals were grand, to say the least: to turn biology into a full-fledged engineering discipline, usually imagined on the analogy of electrical engineering. Or, as the SynBERC Principals sometimes put it, the challenge is to make biology, "easy to engineer" by establishing and circulating standardized materials and know-how.

The SynBERC proposal was enthusiastically received by officials at the NSF. Before making the official award, however, NSF officials informed Jay Keasling, a professor of chemistry at UC Berkeley and the future director of the center, that the award was contingent on including an "ethics" component. Keasling et al. were perfectly willing to accept this proposal although clearly neither the NSF nor 
the principle scientists and engineers who were to direct the Center had a very clear or well-formulated idea about what such a component would look like, or what it would do. Subsequently, the authors of this paper were invited to take up the challenge of designing and experimenting with new forms of collaboration between the life sciences and the human sciences, including ethics. Concurring with the diagnoses of colleagues from ethics and the social studies of science, we agreed that the time seemed ripe to see whether one form or another of "post-ELSI" ethicsconducted alongside of and collaboratively with biologists and engineers - could be invented and implemented for synthetic biology (Khushf 2007; Jasanoff 2005; Nowotny et al. 2001; Gibbons 1999). We proposed the title of Human Practices as a substitute for "ethical and social consequences." In late 2006, "Human Practices" officially became a core research thrust of the Center.

From the outset Human Practices has been designed to focus on reciprocal interfaces between and among synthetic biology and economic, political, and cultural forces, with particular attention to questions of security, new organizational forms, ethics and industrial relations. With others, we have argued that to the extent that its technical goals are achieved, synthetic biology is likely to play a formative role in contemporary human life (Purnick and Weiss 2009; Yearly 2009; O’Malley et al. 2008; Rabinow and Bennett 2007). As such, following the mandate of funders and other thoughtful observers, we insist that technical virtuosity per se cannot be the only measure of success for SynBERC, or for synthetic biology more broadly. Rather, integral to the worth and distinctiveness of synthetic biology is the possibility of elaborating a framing of how science can be undertaken and organized as a comprehensive Human Practice from the outset (Bedau and Parke 2008; Schmidt et al. 2009). But how to make these efforts collaborative remains problematic and the subject of muted contestation.

During 2007 and 2008, efforts at SynBERC (and in other allied venues) shifted from writing and disseminating manifestos and grant proposals to facing the challenges of animating sustained research programs. Investigators began confronting the challenge of making synthetic biology into more than a brand and more than a fundable vision. As the shift from manifestos to research programs has advanced, diverse, if overlapping, scientific and organizational strategies operating under the generic label of synthetic biology have emerged, and salient differences among these strategies are becoming clear. Moreover, these diverse technical and organizational strategies call for corollary strategies for Human Practices engagement. Given the lessons learned from several decades of the social and anthropological study of science, the need for such adjusted ethical and social scientific strategies comes as no surprise. Science
Studies, after all, has demonstrated that the goals and practices of research are oriented and shaped by broader concerns from the outset (Jasanoff 2005; Nowotny et al. 2001; Gibbons 1999). As synthetic biology shifts from manifestos to research programs, its initial directions, distinctiveness and results can now begin to be specified and characterized (Purnick and Weiss 2009; Rabinow and Bennett 2008a). As such, the design specifications needed for appropriate corollary developments in Human Practices can now be specified as well (O'Malley et al. 2008; Schmidt et al. 2009; Rabinow and Bennett 2008b).

\section{In search of synthetic biology: four research programs}

From its inception up to the present, it has been proposed that synthetic biology is one area of post-genomics ripe for designing and inventing distinctive forms for Human Practices (Andrianantoandro et al. 2006; Baker et al. 2006; Endy 2005; Church 2005). Most of the players in this nascent field agree on the need for (a) rationalized design and construction of new biological parts, devices, and systems as well as (b) the re-design of natural biological systems for specified purposes, and that (c) the versatility of designed biological systems makes them ideally suited to solve challenges in renewable energy, the production of inexpensive drugs, and environmental remediation, as well as providing a catalyst for further growth of biotechnology.

What is understood by these goals, however, is quite diverse (Purnick and Weiss 2009; Ross and Arkin 2009; Andrianantoandro et al. 2006). Those assorted understandings are currently contributing to different ramifications of synthetic biology-ramifications that are not only technically and organizationally significant, but ethically, industrially, politically, and environmentally significant as well. In order to clarify this situation, we distinguish at least four design and composition strategies currently operating under the name of synthetic biology: parts, pathways, genomes, and systems. In the section that follows we provide a characterization of each these four strategies, first considering their biological research programs. Then, we provide a synopsis of efforts within these programs that fall under the Human Practices rubric. We pay special attention to externalities (those costs expected to be paid by someone else) as well as critical limitations (the-often unacknowledged-range of structural capacities and incapacities) of each research strategy.

We argue that the challenge of inventing new forms for synthetic biology, forms that incorporate collaboration with human scientists from the outset, cannot be met unless and until salient differences among and across research strategies are specified. We should note for the reader that the four strategies analyzed here are not exhaustive of current 
research in synthetic biology (Purnick and Weiss 2009; Schmidt et al. 2009; O'Malley et al. 2008). We have picked out those strategies which are most directly connected to our efforts at SynBERC. Moreover, we are presenting these strategic orientations as "ideal types." Ideal types are analytic devices constructed so as to sharpen differences in order to make emergent trends easier to characterize. With a diagnostic overview of the objects, methods and purposes in place, researchers will be in a better position to carry out Human Practices inquiry (Weber 1949).

\section{Parts}

The first and most widely publicized research strategy has been formulated by researchers at MIT, and is exemplified by the BioBricks Foundation. This approach has two goals. The first goal is to transform biology into a fully standardized and abstracted engineering discipline understood in a literal sense on the analogy of electrical and computer engineering. The second goal, in line with the first, is to reduce biological systems to modular and additive parts, which can be combined in a linear fashion to form more complex functional units (Canton et al. 2008; Lucks et al. 2008; Endy 2005). ${ }^{1}$ Such standardized biological parts are the principle objects of interest and investment. The success of this approach depends on the ability to black-box the evolutionary contingency and non-linear dynamics of underlying biology, just as, or so the analogy runs, the development of computer software succeeded in blackboxing micro-physics.

In SynBERC, responsibility for designing the partsbased approach — and publicizing it—has been taken up by engineers (electrical and civil) at MIT and Stanford, especially Tom Knight and Drew Endy. A unique contribution of their "Legos" approach has been the development of the "BioBricks" standard as well as the registry of standardized parts (http://parts.mit.edu). The principle vehicle for the expansion and legitimation of this approach is MIT's annual International Genetically Engineered Machines (iGEM) competition. iGEM brings together a growing international set of undergraduate research teams whose projects, in order to qualify, must meet the BioBricks design standardization criteria, and, to qualify for awards, whose parts must be deposited in the BioBricks registry. The iGEM competition constitutes the central venue for establishing the parts-based approach as the norm for synthetic biology.

\footnotetext{
1 As MIT's part's registry puts it, as an: “Assembly of parts into devices and systems is being performed using traditional cloning techniques with a set of restriction sites that allow easy composition of composite devices that, in turn, can themselves be used as parts. Simultaneous parallel assembly lets us build many biological systems quickly" http://www.parts.mit.edu.
}

The manifestos of the BioBricks approach imagine and plot a comprehensive remaking of the biological sciences. Moving from the scale and scope of their guiding vision to more mundane experimental results has encountered research obstacles. Not only are biological processes more difficult to black-box in the lab than in discourse (Lucks et al. 2008; Arkin 2008), but the original and innovative venue lacks the power to enforce its standards. It seems clear that an adequately financed "parts fab" will be required if the BioBricks approach is to be fully vetted and its range of applicability tested. Such a parts fab would be a stable, industrial scale organization with a clear mandate to produce standardized parts (Baker et al. 2006). It would presumably be staffed predominantly with technicians, not undergraduates or post-docs.

\section{Human practices: regulated commons}

The BioBricks vision and its manifestos has been the most comprehensive and inclusive of Human Practices considerations. It explicitly recognizes the need for innovative rethinking of Intellectual Property issues, security concerns, organizational form, and ethics. This vision turns on the idea that in order for synthetic biology to be successfully realized an ethos of openness and collaboration must be fostered from the outset, and venues created for its implementation (Rai and Boyle 2007; Bugl et al. 2007).

A primary externality of the parts approach is that there is no enforcement mechanism connected to the ethos it proposes as the guiding feature of synthetic biology's vision. In the initial stages the expansion of practices of openness and sharing has been dependent on the good will of participants, although attention is beginning to be paid to the pragmatics of organizational enforcement (GanguliMitra et al. 2009). One key critical limitation of the BioBricks approach is its own tacit resistance to establishing a venue in which specialists from the human and socials sciences can play a collaborative and productive role as equal partners. Perhaps a more intransigent obstacle to realizing the ethos of openness is the fact that many of the major players are currently invested in pursuing other IP commitments (O’Malley et al. 2008).

\section{Pathways}

The first completed project that showed that synthetic biology could be a robust and effective approach is the Keasling lab's design of microbial pathways for the production of the precursor to an anti-malaria molecule, artemesinin (Ro et al. 2006). Although the Keasling lab is committed publically to supporting the parts-based approach to synthetic biology, the artemesinin research program was constituted on a different analogical basis. If the analogical basis of the BioBricks 
approach is computer engineering, and the objects it seeks to construct are standard biological parts, the analogical basis of the Keasling lab's approach (an approach shared by the Prather Lab at MIT, among others), is industrial chemistry transferred into the cell (i.e. "microbial chemical factories") and the core objects, on which it focuses its attention and its resources, and around which it has constructed its facility, are enzymatic pathways (Martin et al. 2003, 2009).

A distinctive aspect of the Keasling approach is its venue. The artemesinin project, like Keasling's current work on biofuels (Steen et al. 2008), is set within an institutional framework that allows research to be directly ramified into practical solutions to real world problems. The artemesinin project was organized as a collaborative endeavor by specialists from the Keasling lab at UC Berkeley, the Bill and Melinda Gates Foundation, One World Health, and Amyris Biotechnology. This approach not only enabled the design and development new microbial pathways in yeast (and $E$. coli), but required that essential connections be fashioned from the outset among and between strategic partners. As a result this endeavor set a precedent for the organization of synthetic biology as a collaborative and multi-institutional approach to addressing pressing real world problems. This same approach is now being applied to biofuels at the Keasling-directed Joint Bio-Energy Institute.

A defining characteristic of this pathways based approach is the study of evolutionary processes so that dynamics such as fitness and variation can be leveraged as part of the design toolkit (Yoshikuni and Keasling 2007). Rather than black-boxing biological complexity, evolutionary processes, and variation this approach embraces them in order to produce specified molecular compounds in an efficient and scalable manner.

If the power of this approach is its problem driven focus on pathways, this is also its limitation. The production of enzymes and the reconstruction of pathway dynamics are only one set of processes to be learned from evolution. Although this approach has proven successful in producing high-value compounds such as artemesinin, at present it is not formulating a research program that squarely addresses many of the challenges of constructing yet more complex devices and systems (Purnick and Weiss 2009; Ross and Arkin 2009). This remark is not a criticism, only an observation as to the form and emphasis of the pathways approach.

\section{Human practices: cooperative specialists}

Currently, the Human Practices dimension of the pathways approach recognizes the need to engage specialists for managing financial and regulatory matters as well as the work of developing deliverables. The strength of Keasling's venue is that it considers and accounts for this need by building pathways between the lab and other institutions from the outset such that once the scientific milestones have been reached an apparatus is in place for the translation of the designed pathways into effective solutions.

This arrangement, however, implies an externality. It assumes a cooperative division of labor in which its scientific work assumes a linear and unidirectional relation to the rest of the pathway. The other research departments of Keasling's venues have been designed such that developments in any one area of research can rapidly be accounted for and adjusted to in the other areas of research. Unlike these biological research and engineering departments, those specialists tasked with managing Human Practices issues are downstream and external to the biological research. The price to be paid for such an externality is that while the strength of Keasling's cooperative approach is the anticipation of how to move from the lab to deliverables, its weakness is that if these pathways prove inadequate, there is no available internal mechanism for adjustment.

The success of the artemesinin project covers over the fact that these venues are not as flexible and agile as the actors believe them to be. As such, what is taken to be an acceptable externality in one case-i.e. a cooperative pathway-is structurally assumed to be sufficient in other cases. A key Human Practices critical limitation of the cooperatively constructed pathways approach is that it is not collaborative. By this we mean if the original division of problem areas and specialties proves to be insufficiently agile or flexible, there is no internal mechanism to rethink and implement rapid adjustments. This arrangement is likely to prove troublesome in areas where the scientific product, the regulatory challenges, the financing, the mode and ramifications of applications, and their inter-connections are not known in advance. For example, artemesinin was identified from the start as the malaria molecule of choice, the appropriate funding was non-commercial, and a non-governmental agency (experienced in bio-tech based health care delivery in developing countries) was available. Had any part of this pathway not been already in place, more Human Practices input would have been required. By contrast, in an area such a biofuels where none of the components of the proposed pathways are already in place, and where the contours of the field of ramifications is largely unknown, the smoothness of the previous operations is unlikely to be replicated. In sum, a cooperative state of affairs, taken as sufficient for all cases, becomes a critical limitation and not only an externality.

\section{Genomes}

Another type of research program focuses on the design and construction of "minimal cells." This self-description, however, is somewhat misleading. Actually, the privileged 
objects of study and intervention in these programs are synthetic genomes, which are designed, modified, reconstructed, and synthesized (Gibson et al. 2008; Gabaldon et al. 2008; Forster and Church 2006). The analogical basis of these programs is cloning. The goal is to fashion synthetic genomes so that they can be inserted into and function within existing cellular hosts. The purpose is to leverage cell functions, including mechanisms of self-reproduction and the capacity for adaptation. This whole-genome approach to synthetic biology is predicated on the assumption that existing cellular machinery will function as a predictable and (ultimately) non-problematic biological chassis for these designed genomes. A common feature of these approaches is the claim that enough is known (or will be known) about evolutionary processes and genomic biology to proceed with the construction of synthetic genomes designed for specified functions. It is anticipated that genomes would be versatile as a refactoring machine for synthetic biology.

Two examples of labs using this strategy are those of George Church at Harvard Medical School and the J. Craig Venter Institute. Church, a PI in SynBERC, is directing a project to design and construct a minimal genome "capable of replication and evolution, fed only by small molecule nutrients" (Forster and Church 2006). Given what has been learned from the genome sequencing projects and from the study of directed evolution, the Church lab is attempting to build a minimal genome that can function as a safe and controllable chassis (Tian et al. 2004). Church's minimal genome offers at least two immediate benefits to synthetic biology. First, it demonstrates a strategy for minimizing the scale of complexity in engineering design. Second, from the outset, it is attentive to issues of safety; it has built-in internal control mechanisms based on new nucleotides (that don't exist naturally) that the lab has designed specifically for this purpose.

The J. Craig Venter Institute has set as its goal the construction of artificial genomes that serve as multi-flexed platforms capable of receiving (and continuing to function with) a series of specific molecular inserts-genetic "cassettes" carrying designed functions. The goal, one might say, is to build a prototype organic robot. The Venter Institute has devoted time and resources to charting a wide range of variation and diversity existing in the wild. They have demonstrated that there is an existing dynamic exchange of molecular material in evolutionary regulated milieus. The documentation of these processes is normative in its use of such milieus to argue that a type of genomic experimentation is a naturally occurring phenomenon going on in the wild with salutary evolutionary consequences (Venter 2007). The Venter design and research strategy_as well as its' manifestos-is at the opposite pole of BioBricks within synthetic biology's current field of options. Instead of black-boxing biological processes, Venter's Institute approaches evolutionary resources as a vast lab within which a nearly infinite number of experiments past and present provide invaluable lessons of what nature has allowed is taking place. $^{2}$

\section{Human practices: safety-by-design}

Those currently working on the design of synthetic and artificial genomes devote attention and resources to issues of safety and security, and what they take to be attendant social consequences. Their strategy for addressing these Human Practices concerns can be called "safety-bydesign." 3 There is an explicit effort to design genomes in such a manner so as to maximum control over their functionality. Design attention is devoted to minimizing the risk of survival or re-programmability outside of the lab. Safetyby-design's purpose is the fabricate genomes that when circulated, the effects, both negative and positive, can be accounted for and prepared for in advance (Garfinkel et al. 2007; Church 2005).

The key externality of this approach is that it can only address those aspects of the security challenge that are amenable to technological safeguards (Ganguli-Mitra et al. 2009). Security issues are framed as a problem of dual-use in which the principle challenge arises from the threat of "bad" actors "misusing" technologies created for benevolent purposes. This framing is taken to call for a technological response by existing specialists: can a biological chassis be designed in such a way that it cannot be subsequently "misused"? Other significant aspects of biosecurity, such as challenges associated with the current political milieu, or preparation for unexpected events, which are not amenable to safety-by-design, are externalized.

To the extent that this externality is taken to be generally sufficient, it becomes a critical limitation. That is to say, safety-by-design becomes a critical limitation when it is held that the salient security challenges can be mitigated adequately through technical means, police procedures among and between labs, and trust in the expertise and character of current specialists. Once this externality becomes a critical limitation there are no other human practices resources within this venue readily available for responding to other unexpected and unpredicted ramifications.

\footnotetext{
${ }^{2}$ Existing structures and processes can be either directly taken up or refashioned. Like Keasling, Venter wants to use organisms to produce specific molecules of interest. It is a step beyond redesigning pathways-redesigning genomes is an attempt to control all of the coding and reproduction operation.

3 The expression comes from Chris Kelty and Elise McCarthy, in their unpublished working paper, "Responsibility in Nanotechnology (1)".
} 
Safety-by-design is an attempt to extend self-governance models developed by the 1974 Asilomar conference and its successors. However, the success in managing "experiments of concern" depends on the kinds of venues developed in the 1970s, 1980s and 1990s. The scientific, industrial, and political milieus today are strikingly different. Given the internet and the globalization of science, access to materials and specialized knowledge is widespread. As such, the technical safeguards being developed by those designing genomes can only have limited efficacy. To the extent that these technical procedures give the illusion that security issues amount to the management of "experiments of concern," they themselves function misleadingly as "experiments of reassurance," to coin a phrase. We hold that taking such experiments of reassurance as sufficient, explicitly or otherwise, constitutes the significant critical limitation of a safety-by-design approach.

\section{Systems}

The fourth type of approach in synthetic biology takes as its targeted object neither parts, pathways, nor genomes. Rather, the object of scientific and technological interest is a biological system (often multi-cellular) understood in an evolutionary milieu. Here the aim of synthetic biology is not only to produce intra-cellular functions, but includes the goal of intervention and redesign of whole-cell and multicellular systems as well. Its goal is to discover the extent to which abstraction and standardization of bioengineering is feasible at the systems level. New design and composition techniques as well as collaborative strategies are required to pose the question of standardization and abstraction in a manner that will allow them to be approached experimentally (Purnick and Weiss 2009; Ross and Arkin 2009; Rasmussen et al. 2008).

This approach proceeds by explicitly taking into account the critical limitations of the analogies at work in the other approaches. It acknowledges the heuristic value of analogies from other engineering domains for provisional orientation and initial design. However, it understands that the use of analogies can be mis-leading. It follows that, at the level of specifying design parameters, attention must be paid to the limits of dominant analogies in synthetic biology (computer engineering, microbial chemical factories, cloning) and the extent to which they apply to biological systems.

The Ron Weiss lab at MIT and the Arkin and Anderson Labs at UC Berkeley are prime examples of the systems approach in synthetic biology. Many of the so-called "protocell" projects-efforts to design and build minimal cells-are characteristic of this approach as well (Stano et al. 2008). A shared strategy across these labs is to test familiar engineering goals such as standardization, decoupling, abstraction, predictability, and reliability for biology. The problem is: given the seeming complexity and idiosyncrasy of cellular context, the challenge is to account for, and abstract from, the distinctive characteristics of living systems and to formulate principles of design accordingly (Purnick and Weiss 2009; Lucks et al. 2008; Anderson et al. 2006). By contrast to the other approaches, the notion of cellular context is made an explicit part of the design strategy from the start, and strategically factored in to such challenges as the "the functional definition of devices and modules," and the "rational redesign and directed evolution for system optimization." The purpose of such contextual considerations is to make biological engineering modular and predictable at the level of cell populations as well as individual cells (Andrianantoandro et al. 2006). The Weiss, Arkin, and Anderson labs are distinctive in that they are oriented so as to pose and answer question of the limits of standardization, while at the same time designing specified research projects that are addressed to real-world problems as well as applications that contribute to their solution.

\section{Human practices: moral contract}

Although there are often no explicit statements in the manifestos, personal communications and closer examinations of scientific articles reveal an underlying ethical substrate in which developments in science and significant medical issues are combined in commitment to the common good. The funding of a series of research projects reveals a connection and a commitment to medical issues. For example, a project at the Weiss lab funded by the Cystic Fibrosis Foundation explores signaling systems in bacterial populations so as to design biological interventions that would down-regulate the production of microbial biofilm, a source of great distress for CF patients.

A characteristic approach to issues of Human Practices is in the line of the alliance between patient groups and genome sequencing that was prominent in the 1990s. This alliance consists of patient groups providing funding for research projects that, while not being immediately therapeutic or instrumental, hold a plausible promise of identifying and characterizing the underlying biological conditions within which pathologies develop. Moral commitments are addressed in the form of contractual arrangements wherein research results are made available to more clinically oriented specialists in return for funding (Rabinow 1999).

An externality of this moral-contract approach to human practices is that when there are fundamental shifts or blockages, or for that matter successes, there is frequently no built-in capacity for adjustment between the contractual parties. Consequently, the arrangement either dissolves or must be renegotiated. The researcher in this arrangement is 
bound by the problems and interests of the patient organization; if his or her own research ramifies in other directions, other sources of funding must be found.

A critical limitation of this approach is the tacit assertion that paying the price of externalities frees the research program from having to build collaborative venues within which Human Practices can function as an integral element of research design and priorities. There are parallels to this critical limitation in the recent past: the sequencing projects positioned Human Practices downstream and outside of the design of their own research programs; the partsbased approaches have included Human Practices at the discursive level, but have not involved them in the shift to research programs; the pathways approach has designed and implemented interfaces with Human Practices specialists, but this is cooperative and non-recursive; and synthetic genomic design approaches seek to convert all security problems to technical problems as a way of retaining autonomy (Table 1 ).

\section{Beyond genes and social consequences: a human practices challenge}

What is at stake in synthetic biology's shift from manifestos to research programs? What is the best way to understand them? And how is this shift taking place in Human Practices? In the wake of the various genome sequencing projects of the 1990s, the life sciences are being reconfigured (Gibson et al. 2008; Baker et al. 2006; Rabinow 2002; Brenner 2000). Such reorganization is premised on the assumption that new research infrastructures for postgenomic biology are required to facilitate the design and composition of novel biological systems calibrated to deliver solutions for pressing contemporary issues: cheaper therapeutics, biofuels, mechanisms of bio-security, and a cleaner environment. To date, however, these new infrastructures have frequently lacked (and neglected) adequate corresponding research infrastructures for the human sciences, including ethics.
Historically, the signal achievement of bioethics was its' development of practices, procedures and principles calibrated to specific problems (protection of human subjects in research, issues of justice, the need for bureaucratic norms for health care, etc.) (Jonsen 2003). The founders of both American and European bioethics were keenly aware that this calibration of a mode of ethics and problems, in turn, entailed the construction of specific new venues (e.g. IRBs), distinct modes of collaboration (e.g. advisory government commissions), and particular types of inquiry (e.g. the rise of bioethics as a discipline). Today, it seems not only appropriate — but scientifically and ethically mandatory- to consider in what ways these bioethical practices and venues remain adequate to current conditions, and in what way they require augmentation (Schmidt et al. 2009; Parens et al. 2008; O'Malley et al. 2008; Kleinman et al. 1999). Since the development of the Human Genome Project's ELSI program work in bioethics has frequently rendered the relation of problems and venues invisible or tacit. As such, as changes have taken place at the level of the objects and modes of organization in the biosciences, some practitioners have not shown a strong inclination to animate new, more appropriate and effective modes of production.

After the completion of the Human Genome Sequencing projects, it became clear to most observers (and many participants) that the nucleotide sequences themselves were neither the "Holy Grail" nor the "Code of Codes" that the proponents of the projects hoped they would be. Nor were these seemingly endless strings of base pairs the key to "playing God" or "Franken-futures," as opponents warned (Shreeve 2005; Brenner 2000; Keller 2000). By the early years of the twenty-first century, whatever work these analogies had originally been designed to do, they had become outmoded and mis-leading. It is now clear that the sequence information is one of the most important foundational elements-necessary but hardly sufficient-for constructing a contemporary biology (Rabinow and Dan Cohen 2005). What was missing most conspicuously was a credible scientific program for moving from the hope (and desire) that bio-informatics would provide the technological

Table 1 Comparative table of research programs in synthetic biology

\begin{tabular}{|c|c|c|c|c|c|}
\hline & Problem & Analogy & Venue & Human practice & Externality/critical limitation \\
\hline Parts & $\begin{array}{l}\text { Standardizing biological } \\
\text { units }\end{array}$ & Computer systems & iGEM & $\begin{array}{l}\text { Regulated } \\
\text { commons }\end{array}$ & Non-enforceable venue \\
\hline Pathways & $\begin{array}{l}\text { Designing synthetic } \\
\text { pathways }\end{array}$ & $\begin{array}{l}\text { Microbial chemical } \\
\text { factories }\end{array}$ & Agile assemblage & $\begin{array}{r}\text { Cooperative } \\
\text { specialists }\end{array}$ & Non-recursive pathways \\
\hline Genomes & Designed genomic platforms & Cloning & $\begin{array}{l}\text { Lab Fab (building } \\
\text { prototypes) }\end{array}$ & Safety-by design & Technological reductionism \\
\hline Systems & $\begin{array}{l}\text { Regularizing biological } \\
\text { cybernetics }\end{array}$ & Heuristic use & Traditional & Moral contract & $\begin{array}{l}\text { Insufficient attention to } \\
\text { collaboration }\end{array}$ \\
\hline
\end{tabular}


means to deciphering an ever-increasing quantity of molecular information to a more closely calibrated strategy for laboratory experimentation in the near future. Correlatively, an honest inspection revealed an even bigger gap between the overflow of information and its promised transformation into ameliorative and lucrative applications. Finally, there was an amorphous but haunting awareness that what was required ultimately was a firmer scientific understanding of the material under consideration, an explanatory frame adequate to biological structure and function beyond suggestive statistical correlations and broad generalizations about life.

This over-abundance of data and under-determination of its significance yielded a surfeit of visions cum manifestos. The manifestos were driven by the need to articulate and defend a new mission for the large bureaucracies and their costly technologies and facilities that had been constructed as part of the sequencing projects, by a drive to attract venture capitalists; by a drive to develop and implement research strategies that would be scientifically and financially rewarding, etc. The hectic activity devoted to defining the framing and analogical correlatives of a convincing post-sequencing orientation goes some way to situating the effervescent (and largely evanescent) efforts to brand and promote proteomics, systems biology, gene ontology, synthetic biology, and the like, as the crucial next stage in bringing into existence the hoped for wonder and bounty of a biologically based future of knowledge, health, and wealth, that had been so forcefully articulated and promoted by the proponents of the sequencing projects.

Equally significantly, but with less hoopla, by 2007 the ethics initiatives which had come into existence as part of the sequencing projects-the ELSI (Ethical, Legal, and Social Implications) programs - were also beginning to be critically scrutinized (Jonsen 2003; Rabinow 2002; Evans 2001; Cook-Deegan 1995). These programs were constituted according to the terms of a political agreement among the Human Genome Project funders that ELSI would be supported on condition that it operated downstream of the science and technology, and should concern itself primarily with framing social consequences. In the U.S., demand for re-thinking this approach has come in part from the funders of the 30 odd centers in nano-technology and now in synthetic biology, i.e. the U.S. Congress and the National Science Foundation. At the E.C. and in the U.K., similar initiatives are underway. The E.C., in its 7th framework program, for example, has made it mandatory for new projects in synthetic biology to include specialists on safety, security, and ethics as collaborative partners from the outset. In the U.K., to cite another example, synthetic biologists at Imperial College are constituting a joint research program with social scientists at the London School of Economics.
Hence, a shared challenge now exists in parallel to the challenge of constituting a program for post-sequencing biology: what form should be given to synthetic biology research programs such that they incorporate collaboration with human scientists? Said another way, if today there is a broad consensus that the genome sequences were not the key to life, only the "end of the beginning" of biology as Sydney Brenner put it, then it follows logically at least that the ELSI programs, that were constructed within the political and scientific consensus about the significance of the genome sequencing projects, while continuing to provide useful safeguards and as venues for conducting public conversations, are themselves limited in their scope by their original mandate to operate downstream and outside of the sequencing efforts (Brenner 2000).

Agreeing with Brenner that there is a compelling need for scientists to rethink their understanding of the gene, we argue in a parallel fashion that there is an equally if not more compelling need to rethink the cornerstone concept of ELSI-social consequences. The need for rethinking what is meant by social consequences is actually more compelling because while it is habitual for the biological sciences that outdated concepts, techniques, and infrastructures will sooner or later be replaced, there is no guarantee whatsoever that a parallel process exists for the human sciences.

Such concept work begins with recognizing that the term "social consequences" itself is rhetorically misleading and conceptually inadequate. None of the programs or Centers for synthetic biology are being funded by the U.S. or European governments in order to engage in the untrammeled pursuit of knowledge. As with the Human Genome Project they were established to keep sectors of the economy and its scientific and technological base at the forefront of an ever more competitive global playing field. Scholarship has demonstrated for decades that science and technology are formed by, and ramifies across broader and more tightly connected communities than the downstream positioning entailed in the notion of social consequences accommodates (Daston and Galison 2007; Galison 1987; Latour and Woolgar 1979).

We propose that a more conceptually adequate term would be Human Practices "ramifications." To ramify means to produce differentiated trajectories from previous determinations. This unmooring from previous determinations produces unexpected effects that may complicate a situation or make the desired result more difficult to achieve. One advantage of this term is that, unlike social consequences, it does not imply a downstream positioning of ethics and the human sciences, that would impose an arbitrary hierarchy in which research somehow takes place outside of the conditions and constraints of the larger community. Current strategies for addressing the persistent inequality of power between the biological and human 
sciences, such as SynBERC's Human Practices, position ethics "upstream" and "mid-stream" in its execution and deliverables (Khushf 2007; Rabinow and Bennett 2007; Fisher et al. 2006; Wilsdon and Willis 2004). This positioning, it is argued, is more adequate to the challenge of establishing human scientists as equal and collaborative stakeholders. Moreover, such positioning supports the critical work of documenting and analyzing the actual ethical and social as well as technical and organizational ramifications of research as they unfold.

Of course many other things will follow from scientific developments: discoveries, blockages, power struggles, patents, career moves, etc. Some of these will be planned others not, some predictable others not, some desirable others less so. All of this will depend in large part on the degree of success or failure to achieve results, to meet milestones, to raise money, etc. It is more rigorous to analyze this situation not simply as the cause-and-effect consequences of the production of truth claims in engineering disciplines, but as ramifications to be analyzed and refashioned. Upon reflection, it is obvious that the very same scientific or technological results could be taken up and mobilized in many different directions. Thus, the object of Human Practices research is ramifications not consequences; its method is observational and analytic; its mode is collaborative.

There is a well-established body of scholarship in Europe and the U.S. insisting that contemporary post-genomic research programs can no longer be constituted as they were in the recent past, although many pragmatic obstacles remain in place. ${ }^{4}$ Moreover, there is growing agreement that the challenges of rethinking "the gene" and rethinking "social consequences" as a linked set of problems can no longer being ignored (Ganguli-Mitra et al. 2009; Rabinow and Bennett 2008a; Khushf 2007; Barben et al. 2007; Rose et al. 2006; Nowotny et al. 2001). Interdisciplinary science and Human Practices must be brought into a more productive adjacency if we are to inflect post-genomic biology in a more democratic and ethical fashion (Jasanoff 2005; Hayden 2003; Guston 2000; Lash et al. 1996; Rip et al. 1995). But how to make this task collaborative and synergistic, given enduring power inequalities and entrenched dispositions, remains a challenge. The problem is to conceive of new venues in which such collaboration might

\footnotetext{
$\overline{4}$ The pillars that support genomic sequencing models of organizing scientific research as well as the ethics of such research, while deteriorating, are still standing: first, the generation of interest and ample funding based on manifestos and their skillful dissemination; second, the construction of technology and appropriate facilities (including start-up companies); third, scientific advance that can be articulated with the manifestos; eventually, attention (or lip service) to ethical, legal and social consequences.
}

take place, and to invent the techniques of research and remediation that the demands of the day require.

Open Access This article is distributed under the terms of the Creative Commons Attribution Noncommercial License which permits any noncommercial use, distribution, and reproduction in any medium, provided the original author(s) and source are credited.

\section{References}

Anderson JC, Clarke EJ, Arkin AP, Voigt CA (2006) Environmentally controlled invasion of cancer cells by engineered bacteria. $\mathrm{J}$ Mol Biol 355:619-627

Andrianantoandro E, Basu S, Karig DK, Weiss R (2006) Synthetic biology: new engineering rules for an emerging discipline. Nat Mol Syst Biol 2:E1-E14

Arkin AP (2008) Setting the standard in synthetic biology. Nat Biotechnol 26(8):771-774

Baker D, Church G, Collins J, Endy D, Jacobson J, Keasling J, Modrich D, Smolke C, Weiss R (2006) Engineering life: building a Fab for biology. Sci Am 294:44-51

Barben D, Fisher E, Selin C, Guston D (2007) Anticipatory governance of nanotechnology: foresight, engagement, and integration. In: Hackett EJ (ed) The handbook of science, technology studies, 3rd edn. MIT Press, Cambridge

Bedau M, Parke E (eds) (2008) The ethics of protocells: moral and social implications of creating life in the laboratory. MIT Press, Cambridge

Brenner S (2000) The end of the beginning. Science 287:2173-2174

Bugl H et al (2007) DNA synthesis and biological security. Nat Biotechnol 25:627-629

Burke K (1965) Permanence and change. Bobbs-Merrill, Indianapolis

Canton K, Labno A, Endy D (2008) Refinement and standardization of synthetic biological parts and devices. Nat Biotechnol 26(8): $787-793$

Church G (2005) Let us go forth and safely multiply. Nature 438:423

Cook-Deegan R (1995) The gene wars: how science, politics and the human genome project. Norton, New York

Daston L, Galison P (2007) Objectivity. MIT Press, Cambridge

Endy D (2005) Foundations for engineering biology. Nature 438(7067):449-453

Evans J (2001) Playing god?: human genetic engineering and the rationalization of public bioethical debate. Chicago University Press, Chicago

Fisher E et al (2006) Midstream modulation of technology: governance from within. Bull Sci Technol Soc 26(6):485-496

Forster AC, Church GM (2006) Towards synthesis of a minimal cell. Mol Syst Biol 2:45

Gabaldon T et al (2008) The core of a minimal gene set: insights from natural reduced genomes. In: Rasmussen $\mathrm{S}$ et al (eds) Protocells: bridging nonliving and living matter. MIT Press, Cambridge

Galison P (1987) How experiments end. University of Chicago Press, Chicago

Ganguli-Mitra A, Schmidt M, Torgersen H, Deplazes A, BillerAndorno N (2009) Of Newtons and heretics. Nat Biotechnol 27:321-322

Garfinkel M, Endy D, Epstein G, Freidman R (2007) Synthetic genomics: options for governance. Biosecur Bioterror 4:359-362

Gibbons M (1999) Science's new social contract with society. Nature 402:C81

Gibson D et al (2008) One-step assembly in yeast of 25 overlapping DNA fragments to form a complete synthetic Mycoplasma genitalium genome. Proc Natl Acad Sci USA 105(51):2040420409 
Guston D (2000) Between politics and science: assuring the integrity and productivity of research. Cambridge University Press, New York

Hayden C (2003) When nature goes public: the making and unmaking of bioprospecting in Mexico. Princeton University Press, Princeton

Jasanoff S (2005) Designs on nature: science and democracy in Europe and the United States. Princeton University Press, Princeton

Jonsen A (2003) The birth of bioethics. Oxford University Press, Oxford

Keller EF (2000) The century of the gene. Harvard University Press, Cambridge

Kevles D, Hood L (1992) The code of codes. Harvard University Press, Cambridge

Khushf G (2007) Upstream ethics in nanomedicine: a call for research. Nanomedicine 2(4):511-521

Kleinman A, Fox R, Brandt A (1999) Bioethics and beyond. Deadalus 128(4):69-97

Lash S, Szerszynski B, Wynne B (eds) (1996) Risk, environment and modernity: towards a new ecology. Sage Publications, London

Latour B, Woolgar S (1979) Laboratory life: the social construction of scientific facts. Sage Publications, Beverly Hills

Lucks JB, Qi L, Whitaker WR, Arkin AP (2008) Toward scalable parts families for predictable design of biological circuits. Curr Opin Microbiol 11(6):567-573

Martin JJ et al (2003) Engineering a mevalonate pathway in Escherichia coli for production of terpenoids. Nat Biotechnol 21:796-802

Martin JJ et al (2009) Synthetic metabolism: engineering biology at the protein and pathway scales. Chem Biol 16(3):277-286

Nowotny H, Scott P, Gibbon M (2001) Re-thinking science: knowledge and the public in an age of uncertainty. Wiley-Blackwell, Oxford

O’Malley M, Powell A, Davies J, Calvert J (2008) Knowledgemaking distinctions in synthetic biology. BioEssays 30(1):57-65

Parens E, Johnston J, Moses J (2008) Do we need 'synthetic bioethics'? Science 321(5895):1449

Purnick P, Weiss R (2009) The second wave of synthetic biology: from modules to systems. Nat Mol Cell Biol 10:410-422

Rabinow P (1999) French DNA: trouble in purgatory. Chicago University Press, Chicago

Rabinow P (2002) Anthropos today: reflections on modern equipment. Princeton University Press, Princeton

Rabinow P, Bennett G (2007) From bioethics to human practices, or assembling contemporary equipment. In: da Costa B, Philips K (eds) Tactical biopolitics art, activism, and technoscience. MIT Press, Cambridge

Rabinow P, Bennett G (2008a) Ars synthetica: designs for human practice. Rice University Press and Connexions, Houston

Rabinow P, Bennett G (2008b) Human practices: interfacing three modes of collaboration. In: Bedau MA, Parke EC (eds) The ethics of protocells: moral and social implications of creating life in the laboratory. MIT Press, Cambridge

Rabinow P, Dan Cohen T (2005) A machine to make a future: biotech chronicles. Princeton University Press, Princeton

Rai A, Boyle J (2007) Synthetic biology: caught between property rights, the public domain, and the commons. PLoS Biol 5(3):58

Rasmussen S et al (eds) (2008) Protocells: bridging nonliving and living matter. MIT Press, Cambridge

Rip A, Misa TJ, Schot J (eds) (1995) Managing technology in society. Pinter, London

Ro Dae-Kyun et al (2006) Production of the antimalarial drug precursor artemisinic acid in engineered yeast. Nature 440(7086): 940-943

Ross J, Arkin A (2009) Complex systems: from chemistry to systems biology. Proc Natl Acad Sci USA 106(16):6433-6434

Rose N et al (2006) Special issue on genomics. Biosocieties 1(1)

Schmidt M, Kelle A, Ganguli A, de Vriend H (eds) (2009) Synthetic biology: the technoscience and its societal consequences. Springer Academic Publishing, Berlin

Shreeve R (2005) The genome war, how Craig Venter tried to capture the code of life and save the world. Alfred Knopf, New York

Stano G et al (2008) Semisynthetic minimal cells: new advancements and perspectives. In: Rasmussen S et al (eds) Protocells: bridging nonliving and living matter. MIT Press, Cambridge

Steen EJ et al (2008) Metabolic engineering of Saccharomyces cerevisiae for the production of n-butanol. Microb Cell Fact 7:36

Tian J, Gong H, Sheng N, Zhou X, Gulari E, Gao X, Church G (2004) Accurate multiplex gene synthesis from programmable DNA microchips. Nature 432:1050-1054

Venter C (2007) A life decoded. Viking, New York

Weber M (1949). Objectivity in social sciences and social policy. In The methodology of the social sciences (trans: E Shils, H Finch). The Free Press, New York

Wilsdon J, Willis R (2004) See-through science: why public engagement needs to move upstream. Demos, London

Yearly S (2009) The ethical landscape: identifying the right way to think about the ethical and societal aspects of synthetic biology research and products. Interf J R Acad (published online 15 May 2009)

Yoshikuni Y, Keasling JD (2007) Pathway engineering by designed divergent evolution. Curr Opin Chem Biol 11:233-239 